\title{
Circulating Immune Complexes in Cystic Fibrosis and Their Correlation to Clinical Parameters
}

\author{
MARY L. DISIS, THOMAS L. MCDONALD, JOHN L. COLOMBO, ROGER H. KOBAYASHI, \\ CAROL R. ANGLE, AND SANDRA MURRAY \\ University of Nebraska Medical Center Department of Pediatrics [M.L.D., J.L.C., R.H.K., C.R.A., S.M.] and \\ Department of Medical Microbiology [T.L.M., R.H.K.], Omaha, Nebraska 68105
}

\begin{abstract}
Circulating immune complexes (CIC) have been found to be elevated in individuals with cystic fibrosis (CF). Previous investigators, using a variety of assays, have reported high levels of CIC in as many as $86 \%$ of these patients. Our study followed the progress of 25 patients with $\mathrm{CF}$ over a period of 10 months to determine which, if any, clinical parameters correlated with the occurrence and/or concentration of CIC. Immune complex determinations were performed using a coprecipitation method with equine rheumatoid-complement complex. One hundred percent of the $\mathrm{CF}$ patients had CIC elevated above normal levels, however, levels of CIC did not correlate with the severity of an individual's acute exacerbation. Clinical parameters including pulmonary function tests, vital signs, total serum IgG levels, and other laboratory studies, were obtained on each individual and analyzed with respect to their relationship to $\mathrm{CIC}$. Only four of 38 parameters examined had $p<0.05$. Factors that showed significant correlation to elevated CIC's in the highly elevated portion of our CIC population were 1) poor NIH score, 2) increased patient age, 3) low peak expiratory flow rate, and 4) elevated total serum IgG. These clinical values are associated more with the measurement of chronic disease. These data suggest that CICs cannot be used as an indication of short-term prognosis or as a monitor to follow the course of acute severe lung infections in the CF patient Of interest was the observation that all patients who died during the course of the investigation had CIC levels greater than $80 \mu \mathrm{g} / \mathrm{ml}$. (Pediatr Res 20: 385-390, 1986)
\end{abstract}

\section{Abbreviations}

CF, cystic fibrosis

CIC, circulating immune complexes

$\mathrm{RhC}$, rheumatoid-complement complex

IC, immune complexes

NIH, National Institutes of Health

The possibility of an immunological defect in CF has attracted much investigation in recent years. It is well documented that $\mathrm{CIC}$ are elevated in 40 to $86 \%$ of patients with $\mathrm{CF}$, depending on the investigation (1-6). The initial intent of this investigation was to evaluate the use of $\mathrm{CIC}$ determinations as a clinical measure of $\mathrm{CF}$ exacerbation and response to antimicrobial therapy. For immune complex detection and monitoring the change in CIC our laboratory used a unique reagent, an equine rheu-

Received February 19, 1985; accepted December 24, 1985.

Correspondence Thomas L. McDonald, Ph.D., University of Nebraska Medical Center, Department of Medical Microbiology, 42nd and Dewey Avenue, Omaha, NE 68105. matoid Clq-like protein complex, $\mathrm{RhC}$, that binds to and coprecipitates immune complexes from serum during dialysis. Direct quantitation of the amount of antibody in CICs of a patient's serum is then determined by radial immunodiffusion (7). Our data show the presence of elevated immune complexes in $100 \%$ $(25 / 25)$ of CF patients studied, but the presence of these immune complexes did not correlate with acute lung infection. Detailed analyses were undertaken to determine the clinical parameters that correlated with increased CICs.

In summary, this study shows that elevated CIC levels correlate with decreasing lung function, disease chronicity, and low NIH scores in CF patients. These observations indicate that immune complexes may play an important role in the chronic physiological deterioration of the $\mathrm{CF}$ patient.

\section{MATERIALS AND METHODS}

Patient selection. The $\mathrm{CF}$ population at the University of Nebraska consists of 120 individuals at different stages of their disease process. Patients are evaluated every 3 months and have routine lab work (complete blood count, etc.) assessed every 12 months. Twenty-five individuals from the University of $\mathrm{Ne}$ braska CF Clinic participated in the study. Every CF patient coming into the clinic for routine lab work and regular evaluation, or an exacerbation during the 10 -month period of this study was given the opportunity to enter into the investigation. The patients were included into the study sequentially as they attended the clinic and no attempt was made to be selective. All hospitalized individuals were incorporated into the investigation. Patient ages ranged from 10 to 35 (mean 21) yr with a variety of ages at diagnosis of CF. Diagnosis of the disease was established by clinical criteria and abnormal sweat test determinations (8). Informed consent was obtained from each participant, or if the patient was under the age of 18 , from his or her parents. Seventeen of the 25 patients were seen only as outpatients while eight were hospitalized. NIH scores of the outpatient population ranged from 32 to 95 with an average of 66 . NIH scores of the inpatient population ranged from 19 to 80 with an average of 48.

Serum and clinical parameter collection. Serum samples were collected from the participants at routine clinic visits, every 3 to 4 months, and stored at $-70^{\circ} \mathrm{C}$. If a patient was hospitalized for an exacerbation of pulmonary disease, blood was drawn every 3 to 4 days. Quantitative immunoglobulin levels (IgG and IgM) and CICs were measured on these samples. At the same time blood was drawn for immunoglobulin studies, the clinical parameters listed in Table 1 were measured and recorded. On the hospitalized patients these evaluations were performed every 3 to 4 days.

Immunoglobulin concentrations. Quantitation of serum $\operatorname{IgG}$ and IgM was performed using a modification of the radial immunodiffusion technique of Mancini et al. (7). Determination 
Table 1. Clinical parameters recorded at each CIC determination

\author{
Dates of hospitalizations \\ Total length of hospitalizations \\ Circulating immune complex levels \\ Serum IgG levels \\ Serum IgM levels \\ Patient status: stable or acute \\ NIH score \\ Wt \\ Vital signs \\ Temperature \\ Pulse \\ Respiration \\ Blood pressure \\ Adventitious lung sounds \\ Clear \\ Localized \\ 2-3 lobes \\ Diffuse \\ Retractions \\ None \\ Mild \\ Moderate \\ Severe \\ Laboratory values \\ Urinalysis \\ White blood count \\ Hemoglobin/hematocrit \\ Creatinine \\ Fasting blood sugar \\ Liver enzymes \\ SGOT \\ SGPT \\ GGT
}

Total no. of hospitalizations in past yr

Arterial blood gases

Oxygen and route

Ear and oximetry $\mathrm{SaO}_{2}$

Pulmonary function tests (\% predicted)

Peak expiratory flow rate (liter/min)

Forced expiratory volume (1 s); FEV1

Forced vital capacity (liter); FVC

FEV 1/FVC

Forced expiratory flow (liter/min); FEF (25-75\%)

of serum IgG entailed diluting the sample serum 1:100 and 1:200 to bring the values within range of assay sensitivity. $1.0 \%$ agarose gel (Fisher Scientific, St. Louis, MO) was poured to a 1-mm thickness on gel bond backing (Gel Bond Film, Bio Products, Rockland, ME) and $4 \mu \mathrm{l}$ of each serum dilution was inoculated into separate $4-\mathrm{mm}$ wells cut into the plate. The agarose contained a $0.2 \%$ concentration of antihuman IgG (Melloy, Springfield, VA). Standard curves for IgG were constructed from human IgG of known concentration (Kallestead, Chaska, MN). Determination of serum IgM was performed in the same manner, except the sample sera were diluted 1:20 and 1:40 and a concen- tration of $1.0 \%$ antihuman IgM (Melloy) was used in the $1.0 \%$ agarose gel.

CIC. Immune complex determinations were performed using a coprecipitation method with equine $\mathrm{RhC}$ originally described by McDonald (9). This coprecipitation is independent of complement activation or the amount of monomeric $\operatorname{lgG}$ in the test serum. Briefly, $0.4 \mathrm{ml}$ of a $1 \mathrm{mg} / \mathrm{ml}$ solution of $\mathrm{RhC}$ was incubated with $0.1 \mathrm{ml}$ of the sample serum then dialyzed against $0.05 \mathrm{M}$ Tris $\mathrm{HCl}, \mathrm{pH} 8.2$ for $1 \mathrm{~h}$. Under these buffer conditions, $\mathrm{RhC}$ precipitates immune complexes (9). The RhC-CIC precipitate that resulted from this dialysis was washed twice with dialyzing buffer to remove extraneous serum products and dissolved in $0.3 \mathrm{M}$ ammonium acetate $\mathrm{pH} 7.2$. The antibody content of the dissociated immune complexes was then measured directly by radial immunodiffusion in the manner described above. A positive $\mathrm{CIC}$ test for $\mathrm{IgG}$ antibody was defined as greater than $30 \mu \mathrm{g} / \mathrm{ml}$, which is the mean valve of normal sera +2 SD.

Although not part of this study, our laboratory in collaboration with the Veterans Administration Hospital has compared the $\mathrm{RhC}$ assay to the Raji cell assay for the detection of CIC in human sera. The double blind study was performed on 60 sera from patients hospitalized with Streptococcus pneumonia and sera from 25 healthy donors. Overall, there was a high correlation $(95 \%)$ when comparing the two assays for detecting positive ICcontaining sera from those sera in the 60 sera panel; the $\mathrm{RhC}$ reagent detected elevated CIC levels in 37 of the 40 Raji positive sera (95\% agreement). Twenty-one of the 60 patients sera were negative for CIC's by the Raji test and, of these, 18 were also negative in the $\mathrm{RhC}$ assay ( $86 \%$ agreement).

Although there was good correlation between the Raji and the $\mathrm{RhC}$ assays in detecting IC positive and negative sera, the two assays did not agree in the amount of IC in several of the samples. There appeared to be no obvious pattern in the difference, e.g. the same five samples that contained IC above $200 \mu \mathrm{g}$ by the $\mathrm{RhC}$ assay were positive for IC at the lower limit of the Raji assay. In contrast, four samples that were high for IC by the Raji assay tested much lower in the RhC assay which could indicate that the Raji cell assay and the $\mathrm{RhC}$ measure different types of IC. We do not know if this high correlation between CIC positive and negative sera and the two assays is unique to this disease or will prove to be characteristic of the tests with other diseases.

Statistical methods. The population was divided into three groups based on CIC levels. Group 1 had CIC levels of 30-50 $\mu \mathrm{g} / \mathrm{ml}$; moderately elevated, group 2 had CIC levels between $51-$ $79 \mu \mathrm{g} / \mathrm{ml}$; highly elevated, and group 3 had CIC levels of $80 \mu \mathrm{g} /$ $\mathrm{ml}$ and greater; extreme elevations. The clinical parameters were then compared to each group individually, and then to the population as a whole. Collected data were analyzed using a computer program (SAS-IBM) as modified by the University of Nebraska Computer Center. This program consists of elements from both the Student's 2-tailed $t$ test and the Pearson correlation coefficients computed from linear regression analysis.

\section{RESULTS}

CIC determinations were performed on the sera from 24 clinically normal individuals with the $\mathrm{RhC}$ reagent in order to determine background levels and the variability of the assay. In Figure 1 the data show that the mean normal valve for $\mathrm{CIC}$ determinations for $\mathrm{IgG}$ antibody is $17.5 \mu \mathrm{g} / \mathrm{ml} \pm 5$. Also shown in Figure 1 are the CIC and serum IgG determinations of our $\mathrm{CF}$ population. Although the serum IgG levels were widely variable for individual patients and ranged from 7.5 to $50 \mathrm{mg} /$ $\mathrm{ml}$, there was no correlation between increased levels of serum $\mathrm{IgG}$ and $\mathrm{CIC}$ levels when the CF population was examined as a whole. Further analysis of subdivisions of the populations as detailed in the "Statistical methods" section, however, showed a correlation of increased serum IgG levels with elevated levels of $\mathrm{CIC}$ in the group designated as highly elevated (CIC 51-79 $\mu \mathrm{g}$ / 


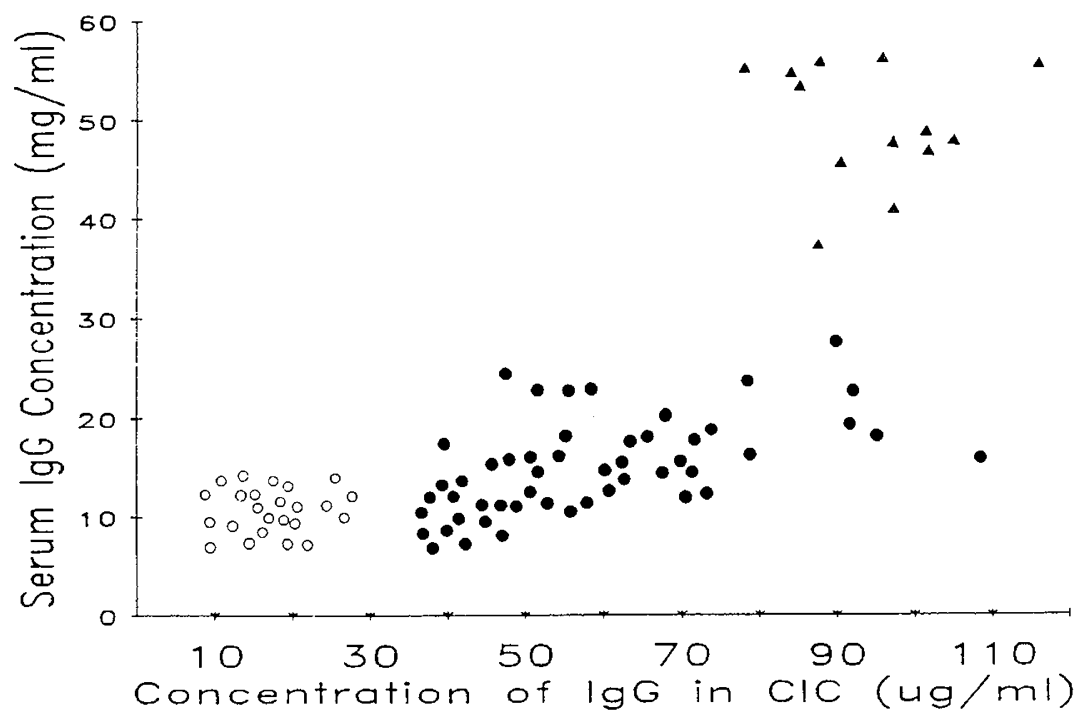

Fig. 1. Levels of serum ICs in both the normal and CF population plotted against total serum IgG determinations. The triangles represent serial collections on the one patient who was hospitalized twice. The circles indicate the other inpatients and all outpatients. The open circles at the left of the graph depict the CIC level data collected from a clinically normal population of 24 individuals (mean CIC value $17.5 \pm 5 \mu \mathrm{g} / \mathrm{ml}$ ).

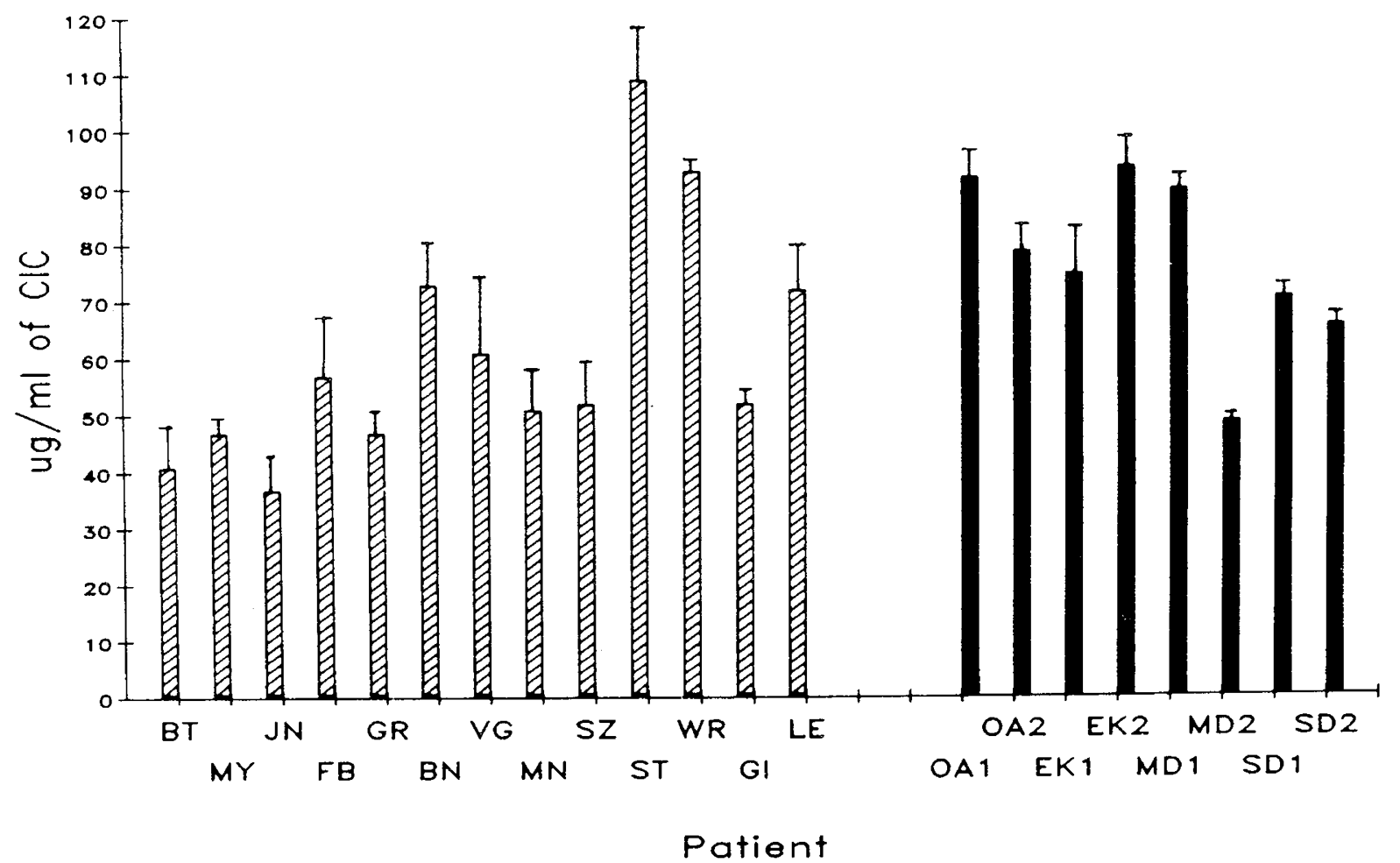

Fig. 2. Levels of serum ICs in CF outpatient population. The error bars represent the SD of the average value of three separate determinations on an individual sample. Bars with hatched lines show those individuals who had only one clinic visit. Solid bargraphs depict values on the first and second clinic visits of four patients; the interval between visits ranged from 3 to 4 months.

$\mathrm{ml}$ ). In addition, the one patient hospitalized twice (data shown with triangles) had a correlation of increased serum IgG with elevated CIC.

The CF patient population was categorized based on the clinical stability of each individual. The first group, the outpatient population, consisted of 17 patients who were never hospitalized during the 10 -month study period. The second group, the inpatient population, was subdivided into those patients hospitalized once and the one patient hospitalized twice.

Figure 2 is a display of the CIC values for the outpatient population. Immune complex levels ranged from 37 to $109 \mu \mathrm{g}$ of CIC per ml of the patient's serum with a mean of $65 \mu \mathrm{g} / \mathrm{ml}$.
These levels were determined by averaging the results of three separate $\mathrm{RhC}$-immune complex determinations on aliquots of the same sample. The SD of three separate assays per individual in the outpatient group ranged from 0 to $\pm 13 \mu \mathrm{g} / \mathrm{ml}$. Four individuals in the outpatient population returned for routine clinic visits at 3- to 4-month intervals during the course of the investigation. Their CIC determinations are depicted in the far right hand side of Figure 2. Examination of the data reveals all CF patients in the outpatient population had elevated levels of immune complexes. It was of interest that the values of the return outpatients, with the exception of the patient MD, were not significantly different after a 4-month interval. 
Figure 3 represents the subset of the inpatient population $(n=$ 7) that was hospitalized once. Immune complex levels for the group taken as a whole ranged from 37 to $78 \mu \mathrm{g} / \mathrm{ml}$ with a SD range of 0 to $\pm 11 \mu \mathrm{g} / \mathrm{ml}$ for three independent determinations on aliquots of the same sample. It is important to note that all patients had immune complex levels greater than normal values. Furthermore, CICs did not decrease to normal range with improvement of the patient's CF exacerbation. VT and AR, for example, had no change in their $\mathrm{CIC}$ levels during hospitalization. Moreover, patients such as HT and SP were dismissed with CIC levels that were higher than those when they entered the hospital.

Figure 4 depicts CIC levels of an inpatient who was hospitalized on two independent occasions. First, there was no significant difference in the CIC values between the patient's initial CIC level of the first hospitalization as compared to the initial value of the second hospitalization, $10 / 24 / 83=88 \pm 8 \mu \mathrm{g} / \mathrm{ml}, 1 / 9 / 84$ $=84 \pm 4 \mu \mathrm{g} / \mathrm{ml}$, respectively. Second, from her entry into the study on $10 / 24 / 83$ to her final sampling on $2 / 24 / 84$ taken 6 days prior to her death, the CIC levels of $\mathrm{NN}$ remained elevated within a $20 \mu \mathrm{g} / \mathrm{ml}$ boundary neither increasing nor decreasing significantly as her clinical condition deteriorated. The IC levels of $\mathrm{NN}$ ranged from 76 to $116 \mu \mathrm{g} / \mathrm{ml}$ during this time.

The second section of the investigation consisted of a computer correlation of the CIC levels just described and clinical parameters recorded. There was no significant difference in CIC levels between the inpatient and outpatient populations. When the population was combined and analyzed as a whole, variables that correlated with increased $\mathrm{ClC}$ levels $(p<0.05)$ were a poor NIH scoring index and increased retractions. The NIH scoring system, also known as the Taussig-Kattwinkel scoring system, is a comprehensive evaluation of CF patients based on pulmonary parameters of disease including radiographic findings and pulmonary function tests, complications that have prognostic significance such as pneumothorax, hemoptysis, cor pulmonale, and general information along with a subjective score for attitude toward their condition (10). A second analysis was performed after dividing the population based on CIC levels. CIC levels of
$30-50 \mu \mathrm{g} / \mathrm{ml}$ were considered moderately elevated and levels greater than $50 \mu \mathrm{g} / \mathrm{ml}$ were considered highly elevated.

With the CF population whose CIC levels were moderately elevated $(n=7)$, there was a significant correlation of increased CIC with number of hospitalizations in the past year, poor NIH score, weight loss, increased long sounds, increased white blood cell count, and a decreased forced vital capacity (Table 2). Also shown in Table 2 are the positive correlations of clinical parameters with the $\mathrm{CF}$ population whose $\mathrm{ClC}$ levels were highly elevated $(n=12)$. With this group there was a significant correlation of increased $\mathrm{CIC}$ with a poor NIH score, decreased peak expiratory flow rate, increased serum $\mathrm{IgG}$, and increasing age.

A third division was made in the CF population based on CIC levels of greater than $80 \mu \mathrm{g} / \mathrm{ml}(n=5)$. Four of the five patients in this group died during the 10-month period of this study and their CIC levels also did not significantly change from the time they entered the study until they died.

\section{DISCUSSION}

Three observations can be made from the raw data of $\mathrm{CIC}$ determinations. First, $100 \%$ of the CF patients in the study had CIC levels greater than the normal population. Second, there was no significant difference in IC levels between patients clinically stable enough to be followed on an outpatient basis and patients in an exacerbation of their pulmonary disease. Finally, levels of CIC taken from an individual over a period of time did not vary widely from their "baseline" despite changes in that patient's clinical condition.

As cited earlier, previous investigators have found elevated CIC in the CF population. Moss et al. (1) state that $86 \%$ of CF patients had elevated CIC levels at some time if studied serially. Our data show all CF individuals in our study had elevated ICs regardless of their clinical status. In most of the previous studies, the assays used for CIC determination are dependent upon either the complement activation properties of the CIC or on methods that detect complexed IgG with antiimmunoglobulins (11-13). In this study, CIC were precipitated from test sera by a reagent,

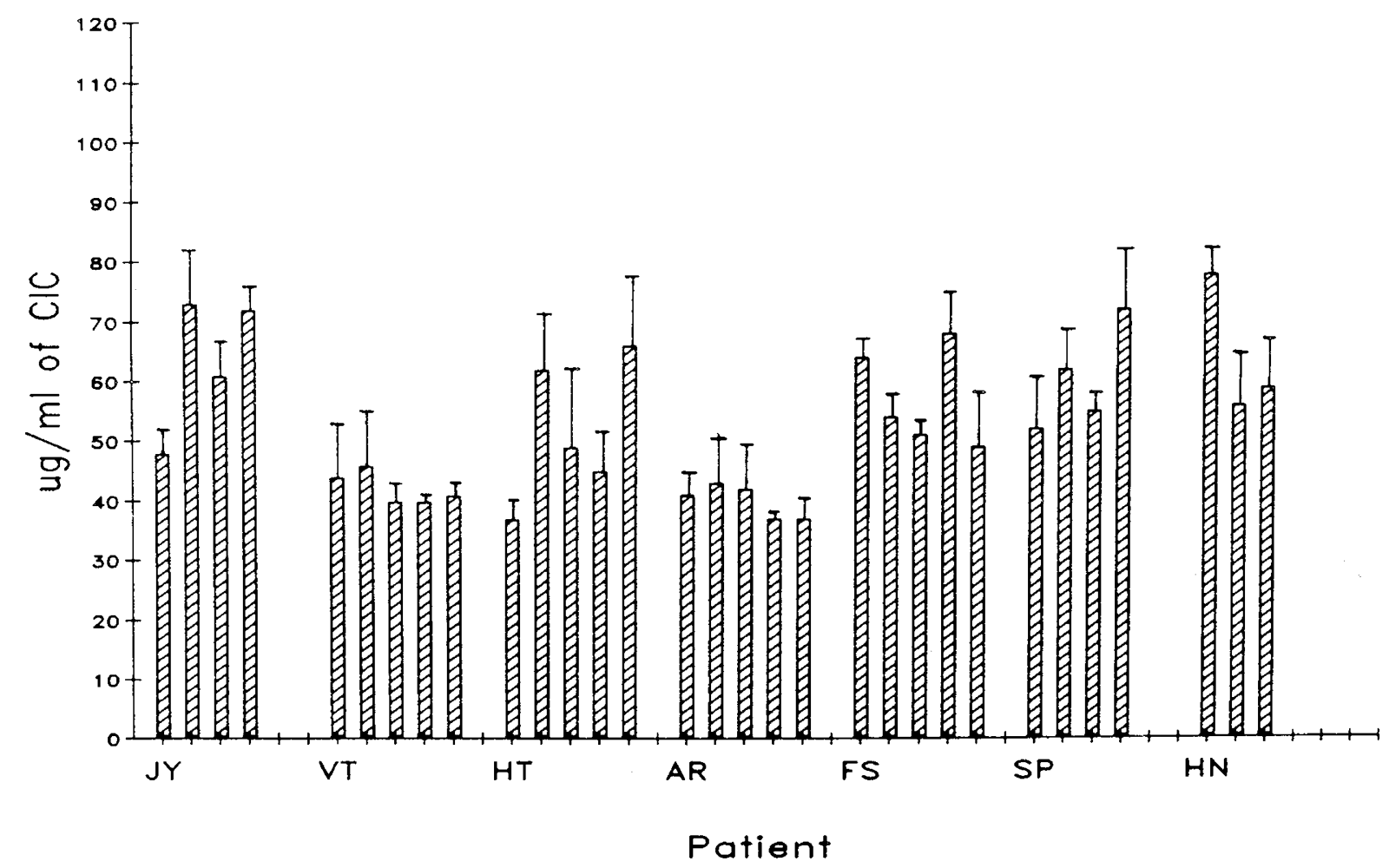

Fig. 3. Levels of serum immune complexes in seven inpatients. Samples for CIC determination were collected at 3- to 4-day intervals during a single hospitalization ( 2 to $3 \mathrm{wk}$ ). The error bars represent the $\mathrm{SD}$ of an average of triplicate assays. 


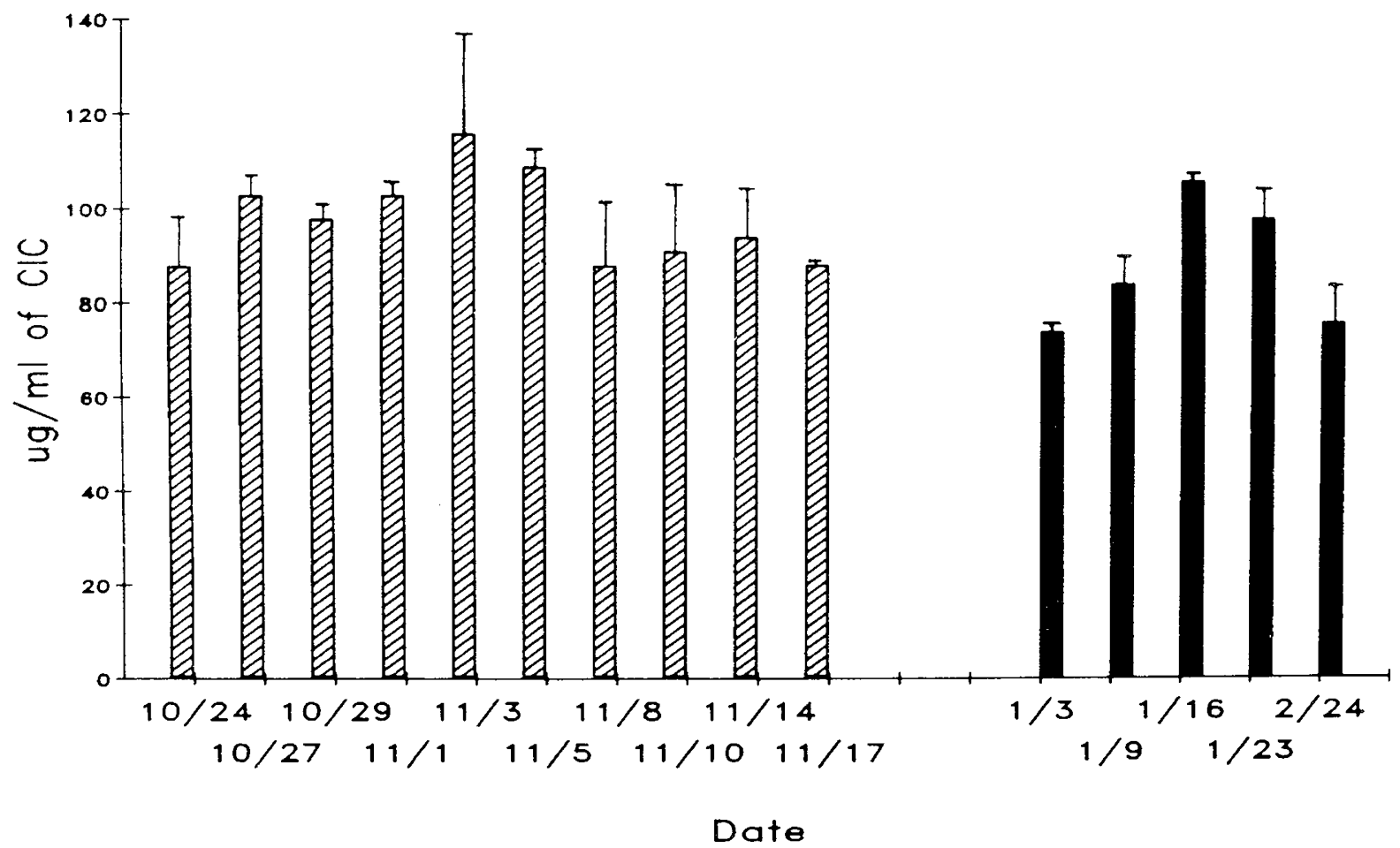

Fig. 4. Levels of serum ICs in one CF patient who was hospitalized on two different occasions. The patient's first hospitalization (hatched bars) began on 10/24/83 and ended 11/17/83. The second hospitalization (solid bars) began on 1/9/84 and ended with the patient's death on $2 / 30 / 84$. The error bars represent the SD of an averaged value of triplicate assays.

Table 2. Clinical parameters that correlated with CIC levels in CF patients

\begin{tabular}{|c|c|}
\hline $\begin{array}{l}\text { Moderately elevated } \\
(\mathrm{CIC}, 30-50 \mu \mathrm{g} / \mathrm{ml})\end{array}$ & $\begin{array}{l}\text { Highly elevated } \\
(\mathrm{CIC}, 50-80 \mu \mathrm{g} / \mathrm{ml})\end{array}$ \\
\hline Hospitalizations* & NIH score* \\
\hline NIH score* & Systolic blood pressure \\
\hline $\mathrm{Wt}^{*}$ & PEFR* \\
\hline Lung sounds* & FEV $1 \dagger$ \\
\hline White blood cells* & FEF† \\
\hline FEV $1 \uparrow$ & $\mathrm{PCO}_{2} \dagger$ \\
\hline $\mathrm{FVC}^{*}$ & $\mathrm{pH} \dagger$ \\
\hline \multirow[t]{2}{*}{ Total serum IgG $\dagger$} & Total serum IgG* \\
\hline & Age* \\
\hline$n=7$ & $n=12$ \\
\hline
\end{tabular}

$\mathrm{RhC}$, and quantitated by determining the amount of complexed human immunoglobulin in a radial immunodiffusion assay. The $\mathrm{RhC}$ is a protein complex purified from horse serum and has two major characteristics that warrant its utility as an IC detecting reagent. First, $\mathrm{RhC}$ is soluble in $50 \mathrm{mM}$ Tris- $\mathrm{HCl}$ buffer containing $0.5 \mathrm{M} \mathrm{NaCl}(\mathrm{pH} 8.0)$ and insoluble in the same buffer without $\mathrm{NaCl}$. In its soluble form $\mathrm{RhC}$ has a high affinity for complexed immunoglobulin and a low affinity for monomeric immunoglobulin (9). Second, when added to test sera, RhC binds ICs and coprecipitates them after the buffer conditions are changed by dialysis to $50 \mathrm{mM}$ Tris- $\mathrm{HCl}$ without $\mathrm{NaCl}(\mathrm{pH} 8.0)$. This reagent has been used extensively in our laboratory for analysis of CIC in diabetic hamsters (14), diabetic rats $(15,16)$, dogs with dermatomyocitis (17), mice with different tumor types (18), and we have recently adapted the assay for $\mathrm{CIC}$ determinations in human serum (19). RhC is stable when stored below $0^{\circ} \mathrm{C}$ in 50 $\mathrm{mM}$ Tris- $0.5 \mathrm{M} \mathrm{NaCl}$ buffer, $\mathrm{pH} 8.0$, and the assay has been shown in this study as well as others (14-19), to be highly efficient, reproducible, and independent of serum immunoglobulin concentration.

The finding that there is no significant difference in the CIC levels between outpatients and inpatients is an important one. Not every patient was colonized with Pseudomonas aeruginosa or Staphylococcus aureus during the time of the investigation. LG (Fig. 2), for example, had a CIC level of $72 \pm 8 \mu \mathrm{CIC} / \mathrm{ml}$ yet a sputum culture at the time of CIC determination yielded normal flora. Previous studies have linked increased $\mathrm{CIC}$ with microbial lung infections $(2,20)$, however, many of our outpatients were not overtly infected. This observation along with our finding that levels of $\mathrm{CIC}$ taken from an individual over a period of time did not fluctuate greatly from their "baseline" indicates the CIC in CF patients may not occur as a result of acute reactants such as those produced during a microbial infection. It could, however, be explained by a continued antigen presence. Recent evidence indicates endogenous antigens may play an important role in the pathogenesis of the disease $(21,22)$. Many studies have been undertaken to determine the antigen(s) in the CIC of CF patients $(4,21-23)$. Although $P$. aeruginosa and $S$. aureus antigens have been found, the amount of antigen detected in many cases cannot explain the entire amount of CIC (20). Autoantibodies against DNA, reticulins, and the pancreas have been implicated as possible causes for elevated levels of immune complexes $(21,24,25)$.

The constant deposition of CIC in various organ systems could be a primary factor in the development of the serious sequelae associated with CF. The few autopsy studies performed investigating the deposition of $\mathrm{CIC}$ in the organs of $\mathrm{CF}$ patients provide a wide variety of results and conflicting answers (26-29).

Examination of the computer analysis reveals a strong association between increased CIC levels and the chronicity of the disease process. Certainly elevated $\mathrm{CIC}$ is not specific for $\mathrm{CF}$, indeed, elevated immune complexes are found in many chronic disease states including other pulmonary disorders (30-32). Elevated levels in $100 \%$ of patients, however, suggest a stronger role for ICs in explaining the pathogenesis of CF. Hodson (33) raises an excellent question: are the immunological abnormalities a 
result of the disease or the cause? A clue to the answer will come when newly diagnosed infants are tested for CIC. If ICs are not related solely to ongoing infection then perhaps immunosuppressive drugs may have the same impact on the CF patient as antibiotics did $20 \mathrm{yr}$ ago. Our data and resultant analysis indicate that $\mathrm{CIC}$ may have a more important role in $\mathrm{CF}$ then just a physiological reaction to chronic lung infection.

\section{REFERENCES}

1. Moss RB, Yao-Pi Hsu, Lewiston N $1981{ }^{125}$ I-Clq binding and specific antibodies as indicators of pulmonary disease activity in cystic fibrosis. Pediatrics 99:215-222

2. Berdischewsky M, Pollack M, Young LS, Chia D, Osher AB, Barnett EV 1980 Circulating immune complexes in cystic fibrosis. Pediatr Res 14:830-833

3. Moss RB, Lewiston N 1980 Immune complexes and humoral response to pseudomonas aeruginosa in cystic fibrosis. Am Rev Respir Dis 121:23-29

4. Moss RB, Yao-Pi Hsu 1982 Isolation and characterization of circulating immune complexes in cystic fibrosis. Clin Exp Immunol 47:301-308

5. McFarlane H, Holzel A, Brenchley P, Allan JD, Wallwork JC, Singer BE, Worsley B 1975 Immune complexes in cystic fibrosis. Br Med J 1:423-428

6. Manthei U, Taussig LM, Beckerman RC, Strunk RC 1982 Circulating immune complexes in cystic fibrosis. Am Rev Respir Dis 126:253-257

7. Mancini G, Carbonara AO, Heremans JF 1965 Immunochemical quantitation of antigens by single radial immunodiffusion. Immunochemistry 2:235

8. Gibson LE, Cooke RE 1959 Test for concentration of electrolytes in sweat in cystic fibrosis of the pancreas utilizing pilocarpine by ionthophoresis. Pediatrics 23:545

9. McDonald TL 1981 Isolation of immune complexes by an equine Clq-like factor. Immunol Comm 10:741-752

10. Taussig LM, Kattwinkel J, Friedewald WT, Di Sant'Agnese PA 1982 A new prognostic score and clinical evaluation system for cystic fibrosis. J Pediatr $82: 380-390$

11. Klein M, Simmovitch KJ 1981 The significance and limitations of current methods for detecting circulating immune complexes. Rheumatology 8:188192

12. Ritzman SE, Daniels JC 1982 Immune complexes: characteristics, clinical correlations, and interpretative approaches in the clinical laboratory. Clin Chem 28:1259-1271

13. Blackstock R 1981 In vitro methods for detection of circulating immune complexes. Ann Clin Lab Sci 44:262-268

14. McDonald TL, Quenette L, Phares CK 1983 Isolation quantitation of immune complexes in diabetic Syrian hamsters: a chronological study. J Clin Lab Immunol 11:129-133
15. Thiele GM, McDonald TL, Crouse DA 1982 Immunoglobulin subclasses of $\mathrm{IgG}$ in serum, CIC, and urine of diabetic rats. Fed Proc 42:422

16. Thiele GM, McDonald TL, Crouse DA 1984 The role of IgG antibody subclasses in the development of diabetic nephropathy. Fed Proc 43:1613

17. Haupt KH, Prieur DJ, Hargis AM, Cowell RL, McDonald TL, Werner LL Evermann JF 1985 Familial canine dermatomyositis, part two: clinical pathologic, immunologic, and serologic studies. Am J Vet Res (in press)

18. McDonald TL, Collins M, Talmadge J 1984 Comparison of antibody isotypes in sera and CIC during tumor growth and metastases of three tumor models in mice. Cancer Res 44:4933-4937

19. Mellencamp MA, McDonald TL, Preheim LC 1984 Circulating immune complexes in patients with pneumococcal infections. Am Soc Microbiol Abstr E-72:80

20. Pitcher-Wilmott RW, Levinsky RJ, Matthew DJ 1982 Circulating soluble immune complexes containing pseudomonas antigens in cystic fibrosis. Arch Dis Child 57:577-581

21. Schiotz PO, Hoiby N, Permin H, Wiik A 1979 Autoantibodies in serum and sputum from patients with cystic fibrosis. Acta Pathol Microbiol Scand [Sect C] $87: 319-324$

22. Hodson ME, Turner-Warwick M 1981 Autoantibodies in cystic fibrosis. Clin Allerg 2:565-570

23. Fosth A, Kollberg H 1980 Autoantibiotics to Tamm-Horsfall protein patients with cystic fibrosis. Acta Paediatr Scand 69:189-192

24. Wallwork JC, Brenchley P, McCarthy J, Allan JD, Moss D, Ward AM, Holzel A, Williams RF, McFarlane H 1974 Some aspects of immunity in patients with cystic fibrosis. Clin Exp Immunol 18:303-320

25. Murray MJ, Thal AP 1960 The clinical significance of circulating pancreatic antibodies. Ann Intern Med 53:548

26. Davis CA, Abramowsky CR, Swinehart G 1984 CIC and the nephropathy of cystic fibrosis. Hum Pathol 15:244-247

27. Abramowsky CR, Swinehart G 1982 The nephropathy of cystic fibrosis: a human model of chronic nephrotoxicity. Hum Pathol 13:934-939

28. Michalsen H, Monn E, Bergan T, Churg J, Johannessen JV 1984 Renal biopsies in cystic fibrosis. Pathol Res Pract 178:261-267

29. Vawter GF, Shwachman H 1979 Cystic fibrosis in adults: an autopsy study. Pathol Ann 14[Pt 2]:357-82

30. Tomasi TB, Fudenberg HH, Finby N 1962 Possible relationship of rheumatoid factors and pulmonary disease. Am J Med 33:243

31. Benzonana G, Carpentier N, Jeannet M, Lambert PH, DeMoerloose $P$, DeWurstemberger B, Leski M $1981 \mathrm{CIC}$ in dialyzed patients waiting for renal transplantation. Transplant Pro XIII:000-000

32. Krapf F, Renger D, Schedel I, Leiendecker K, Leyssens H, Deicher H 1982 A PEG-precipitation laser nephelometry technique for detection and characterization of CIC in human sera. J Immunol Meth 54:107-117

33. Hodson ME 1980 Immunological abnormalities in cystic fibrosis: chicken egg? Thorax 35:801-806 